\title{
Gas Delivery System Device
}

National Cancer Institute

\section{Source}

National Cancer Institute. Gas Delivery System Device. NCI Thesaurus. Code C50314.

A system designed to supply a gas flow to another device or system. 